\title{
ANALYSIS ON THE WIND-BLOWN SAND ENTERING THE RESERVOIR OF SANSHENGGONG WATER CONTROL PROJECT
}

\author{
LI, Z. Q. ${ }^{1,2}-\mathrm{LI}, \mathrm{Q} . \mathrm{Y}^{3^{*}}-\mathrm{WANG}, \mathrm{Y} . \mathrm{M}^{1}{ }^{1}-\mathrm{LIU}, \mathrm{L} . \mathrm{H}^{4}$ \\ ${ }^{1}$ School of Water Resources and Hydropower, Xi'an University of Technology, Xi'an 710048, \\ China \\ ${ }^{2}$ Huangzangsi Project Construction \& Management Bureau, HRB, Lanzhou 730030, China \\ ${ }^{3}$ Henan Vocational College of Water Conservancy and Environment, Zhengzhou 462000, China \\ ${ }^{4}$ North China University of Water Resources and Electric Power, Zhengzhou 450045, China \\ *Corresponding author \\ e-mail: 46189156@qq.com
}

(Received $18^{\text {th }}$ Mar 2019; accepted $17^{\text {th }}$ May 2019)

\begin{abstract}
Considering the potential threats of wind-blown sand to the reservoir capacity of Sanshenggong Water Control Project (SWCP), this paper calculates the amount of wind-blown sand in the reservoir based on the change of reservoir capacity, using sand balance method and cross-section method. Then, the calculated amount was compared with the amount of wind-blown sand measured through field monitoring. Synthesizing the calculation results of the three methods, it is considered that the amount of wind-blown sand into the reservoir is about $0.7 \sim 1$ million tons per year. The research findings provide a good reference for silt prevention.
\end{abstract}

Keywords: sand balance method, sand flow, the yellow river, cross-section method, field monitoring

\section{Introduction}

Located near the Yellow River, the Ulan Buh Desert is widely known for limited rainfall, high evaporation rate and frequent gales (Chen et al., 2016). Each year, a lot of sand is blown from the desert into the Yellow River, making the desert a major source of sediment in the river. Wind erosion in this area has attracted much attention from the academia, yielding successful researches on the hazards and control of wind erosion, the law of sand dune movement and the physical features of sand. However, there is no quantitative analysis on these movements and features (Chen et al., 2015; Yin et al., 2017).

The sand from the desert has many negative impacts on Sanshenggong Water Control Project (SWCP), a local water conservancy project on the main stream of the Yellow River in Daokou, Bayannur, Inner Mongolia. The main function of the project is diversion and irrigation, which relies heavily on reservoir capacity. The silt in the SWCP reservoir mainly come from the sediment of upstream water and the windblown sand from Ulan Buh Desert.

Considering the features of reservoir deposition, this paper calculates the amount of wind-blown sand in the reservoir based on the change of reservoir capacity, using sand balance method and cross-section method. Then, the calculated amount was compared with the amount of wind-blown sand measured through field monitoring (Youssef et al., 2012). 


\section{Materials and methods}

\section{Study area}

With an elevation of $1,052 \mathrm{~m}$, the SWCP $\left(40^{\circ} 18^{\prime} 42^{\prime \prime} \mathrm{N}, 107^{\circ} 01^{\prime} 39^{\prime \prime} \mathrm{E}\right)$ controls a $314,000 \mathrm{~km}^{2}$ basin area. It is a low-head diversion project with irrigation as its main function. The other functions include navigation, transport, power generation and industrial water supply. The project was constructed between 1959 and 1961 (Mao, 2013). The storage capacity was designed as 0.8 billion $\mathrm{m}^{3}$ (Liu et al., 2016), and stands at 0.952 billion $\mathrm{m}^{3}$ under the normal storage level of $1,055.0 \mathrm{~m}$.

Located at the entry of the SWCP reservoir, the Dangkou Hydrological Station marks the start of the backwater area, which extends $53.8 \mathrm{~km}$ before reaching the end at the dam site of the SWCP. The SWCP reservoir is a plain river reservoir with an average width of 2,000 m, half of which belongs to the main channel. The project area has a continental monsoon climate in the middle temperate zone. The left and right banks of the project area are a flat beach of sediment and an Ordos terrace, respectively.

The SWCP provides an important guarantee for irrigation in the Hetao region in the upper reaches of the Yellow River, which used to suffer from frequently droughts and floods, and greatly lowered the amount of sand in the diversion canal. Statistics show that the amount of sand in the main channel of the Yellow River in the Hetao section has been reduced by $60 \%$ since the completion of the SWCP (Mao, 2013). The decline in sedimentation saves lots of irrigation cost.

\section{Data collection}

The research data were extracted from the Validated Data Compilation (1961 2000) of the SWCP in Inner Mongolia Reaches of the Yellow River, the hydrological data (1962 2014) of Dangkou Hydrological Station, the Sediment Source and Siltation Change in Ningxia-Inner Mongolia (NIM) Reaches of the Yellow River and the Feasibility Study Report on Phase 2 Flood Control Project in Inner Mongolia Reaches of the Yellow River. Meanwhile, the amount of wind-blown sand into the SWCP reservoir was calculated from the field measured data.

The amount of wind-blown sand into the SWCP reservoir was calculated three times, respectively through the combination of sand balance method and cross-section method, the storage capacity method and field observation.

\section{Sediment balance method and cross-section method}

Sediment balance method and cross-section method (a.k.a. the topographic method) are two popular ways to compute the amount of sand in a river section.

\section{Sediment balance method}

By this method, the amount of sand in the river section $\Delta W_{s}$ is calculated from to the amount of sand entering and leaving the river section, as shown in Equation 1:

$$
\Delta W_{S}=W_{\mathrm{j}}+W_{h}-W_{c}-W_{y}
$$

where $W_{j}$ is the amount of sand entering the reservoir at the entrance; $W_{h}$ is the amount of sand entering the reservoir from the tributaries; $W_{c}$ is the amount of sand leaving the river section at the exit; $W_{y}$ is the amount of sand diverted away from the reservoir. 
In the SWCP reservoir, there is no tributary that transports sand into the river section. Rather, lots of sand are blown by wind from the banks into the Yellow River. Hence, the above formula should be revised by replacing the $W_{h}$ with the amount of windblown sand $W_{f s}$, as shown in Equation 2:

$$
\Delta W_{S}=W_{\mathrm{j}}+W_{f s}-W_{c}-W_{y}
$$

\section{Cross-section method}

The cross-section method is implemented in the following steps: selecting several cross-sections from the river section, measuring the topography of each cross-section before and after a time period, obtaining the silting area of each cross-section in that period (Thomas, 2011), calculating the sand amount of the river channel between these cross-sections, and deriving the total amount of sand in the entire river section in that period. The cross-section method can be divided into several categories, as shown in Equations 3 and 4.

(1) Trapezoidal method

$$
\sum_{i=1}^{n} V_{i}=\sum_{i=1}^{n-1} \frac{1}{2}\left(\Delta A_{i}+\Delta A_{i+1}\right) \times \Delta L_{i}
$$

where $\mathrm{V}_{\mathrm{i}}$ and $\Delta A_{i}$ are the sand amount and silting area of the $\mathrm{i}$-th cross-section, respectively; $\Delta A_{i+1}$ is the silting area of the $\mathrm{i}+1$-th cross-section; $L_{i}$ is the distance between the first and $\mathrm{i}+1$-th cross-sections; $\mathrm{N}$ is the number of cross-sections. In this method, the river section between two adjacent cross-sections is viewed as a trapezoid for sand amount computation.

(2) Cone method

$$
\sum_{i=1}^{n} V_{i}=\sum_{i=1}^{n-1} \frac{1}{3}\left(\Delta A_{i}+\Delta A_{i+1}+\sqrt{\Delta A_{i} \times \Delta A_{i+1}}\right) \times \Delta L_{i}
$$

The parameters are the same as those in Equation 3 above.

\section{Comparison between the two methods}

The sand balance method and cross-section method have their respective merits and defects. The sand balance method is suitable for calculating the sand amount in different periods, especially in short periods. However, some systematic errors may occur in the computation, and the calculated amount may deviate from the actual amount if there are any uncontrolled areas. As for the cross-section method, the calculation accuracy is affected by the sparse layout of cross-sections and the limited number of measuring points. The error of this method will be magnified by a low amount of sand. Through repeated comparison, most researchers agree that the two methods have basically the same computing accuracy.

In this paper, the two methods are adopted to calculate the amount of wind-blown sand into the SWCP reservoir. Firstly, the sand amount of the reservoir was computed by the cross-section method. The result is the sand amount in the river section $\Delta W_{s}$, which contains the wind-blown sand. Since the cross-section method cannot determine 
the specific amount of wind-blown sand, the sand balance method was introduced to calculate the amount of sand leaving the river section at the Daokou Hydrological Station $W_{c}$ and the amount of sand diverted away from the reservoir $W_{y}$. Then, the amount of wind-blown sand was computed by subtracting the amount of sand entering the reservoir at the entrance $W_{j}$ from the total amount of sand leaving the reservoir $W_{c}$ and $W_{y}$.

\section{Storage capacity method}

Based on the features of water and sand flows, the storage capacity method computes the annual mean runoff and the sand transport in each period of the past years, and determines the amount of wind-blown sand into the study area according to the siltation of the reservoir section (Chattopadhyay, 2011). The calculation formula is shown in Equation 5:

$$
S_{\text {win }}=\frac{r \times H \times L \times B \times R_{c}}{R}
$$

where $S_{\text {win }}$ is the amount of wind-blown sand entering the Yellow River $(103 \mathrm{~kg}) ; \gamma$ is the volume of the wind-blown sand $\left(1.4 \times 103 \mathrm{~kg} / \mathrm{m}^{3}\right) ; \mathrm{H}$ is the sedimentary thickness $(\mathrm{m})$; $\mathrm{L}$ is the length of the river section affected by the sand blown from the desert (m); $\mathrm{B}$ is the width of the river section $(\mathrm{m}) ; R_{c}$ is the proportion of wind-blown sand in the total amount of sand in the river section $(61 \%)$; $\mathrm{R}$ is the proportion of wind-blown sand that deposited in the river section in the total amount of wind-blown sand (70.74\%).

\section{Field observation}

Established in 2011, Ulan Buh Desert Wind and Sand Comprehensive Observation Base monitors eleven types of land uses, including the mobile, semi-mobile, fixed and semi-fixed sand dunes in the study area. The observation plots cover typical areas with similar topography. The volume of wind-blown sand was recorded by the wind-sand collector, and then the transport rates of wind-blown sand were computed for different kinds of sand dunes, eliminating the volume in invalid wind directions (Kisi, 2014).

In 2014, several $10 \mathrm{~m}$-tall wind-blown sand flux towers were set up along the Yellow River to observe the settlement of suspended particles in the wind-blown sand. These towers were arranged in a straight line pointing toward the northwest direction. The observation lasted from May 26, 2014 to May 26, 2015. The annual sand flow at the height of 1 10 m were observed on the left and right banks. The amount of Suspended sand entering the Yellow River $S_{\text {sus }}(\mathrm{t} / \mathrm{yr})$ can be calculated as shown in Equation 6:

$$
S_{\text {sus }}=\left(S_{l}-S_{r}\right) \times L
$$

where, $S_{i}$ and $S_{r}$ are the amounts of sand entering the river from the left bank and the right bank, respectively $(\mathrm{kg} / \mathrm{m} / \mathrm{yr})$; $\mathrm{L}$ is the length of the river section affected by the sand blown from the desert $(\mathrm{km})$ 


\section{Results}

\section{Features of wind-blown sand into the reservoir}

The water and sand in the SWCP reservoir can be traced to different sources. About $99 \%$ of water and $44 \%$ of sand in this river section come from the reaches above Lanzhou. Due to the completion of several water conservancy projects in the upper reaches (Longyangxia Reservoir and Liujiaxia Reservoir), the amount of water entering the SWCP reservoir has been decreasing year by year.

In the SWCP reservoir, the perennial mean water inflow of the reservoir has dropped from 30.312 billion $\mathrm{m}^{3}$ before 1981 to 30.094 billion $\mathrm{m}^{3}$ in 1981 1990, 21.277 billion $\mathrm{m}^{3}$ in 1991 2000, and 193.69 billion $\mathrm{m}^{3}$ in 2001 2010, despite a slight increase to 26.489 billion $\mathrm{m}^{3}$ after 2011. Overall, the water inflow in 1991 2000 is $29.30 \%$ lower than that in 1981 1990. The minimum water inflow appeared in 1997, which is only 16.4 billion $\mathrm{m}^{3}$. The reduction in water inflow is accompanied by the stabilization of inflow and water volume. In 2012, the main stream in the upper reaches saw the biggest flood since 1989. In the Ningxia-Inner Mongolia reaches of the Yellow River, the water flow remained above $2,000 \mathrm{~m}^{3} / \mathrm{s}$ for 48 consecutive days, pushing up the annual total water flow to 32.907 billion $\mathrm{m}^{3}$, the highest level since 1989 .

The sand inflow into the SWCP reservoir peaked in the 1960s, and decreased continuously ever since. Despite the slight recovery of water inflow after 2010, the sand inflow into the reservoir remained at a very low level. In 2011 2014, the sand inflow was merely 0.28 billion tons, about $16.57 \%$ of the sand inflow in the 1960 s. Even if a major flood occurred in 2012, the sand inflow was only 0.48 billion tons in that year, which is lower than that in other years with smaller water flow. The sand inflow was further suppressed in 2014, due to the completion of the Haibowan Water Conservancy Project. In that year, the annual sand inflow at Dangkou Hydrological Station reached the lowest point (105 million tons) since the 1960s.

The water and sand inflow features of the SWCP reservoir in each period are presented in Table 1. Judging characteristic by the perennial variation in water and sand inflows, the water and sand conditions of the SWCP reservoir are favorable for longterm maintenance of the storage capacity.

Table 1. Features of water and sand inflows to the SWCP reservoir

\begin{tabular}{c|c|c}
\hline Time slot & Average annual runoff $\left(\mathbf{1 0}^{\mathbf{8}} \mathbf{m}^{\mathbf{3}}\right)$ & Average annual sediment transport $\left(\mathbf{1 0}^{\mathbf{8}} \mathbf{t}\right)$ \\
\hline $1962-1970$ & 317.62 & 1.69 \\
$1971-1980$ & 288.61 & 0.9 \\
$1981-1990$ & 300.94 & 0.99 \\
$1991-2000$ & 212.77 & 0.95 \\
$2001-2010$ & 193.69 & 0.53 \\
$2011-2014$ & 264.89 & 0.28 \\
\hline
\end{tabular}

\section{Reservoir siltation}

Since the SWCP entered service, the sand amount in the reservoir is mainly affected by the inflow of the upstream water. Generally, a large inflow brings about scouring and a small inflow leads to silting. So far, the SWCP reservoir has mainly suffered from 
silting. As shown in Figure 1, the storage capacity of the reservoir has changed since its completion. The siltation of the reservoir can be divided into the following phases.

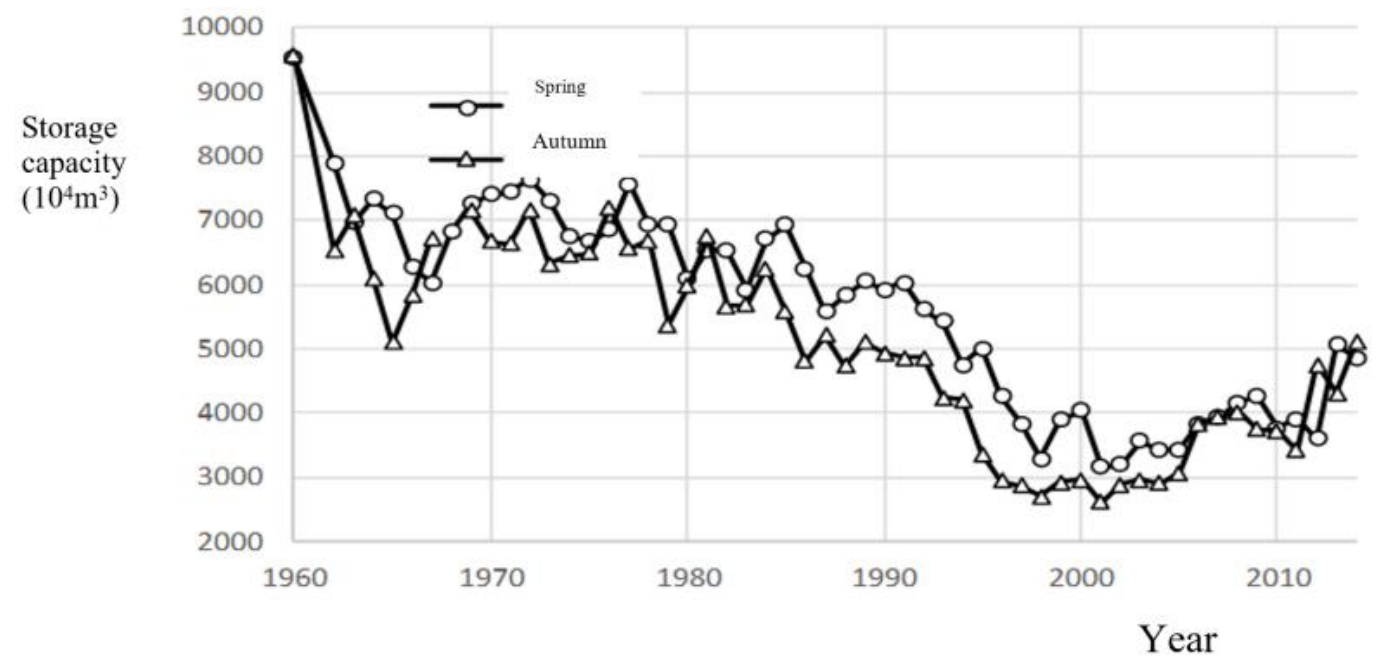

Figure 1. Variation of storage capacity in the SWCP reservoir

\section{(1) Spring 1961 spring 1965}

In the years right after the completion of the SWCP, the water flow rate and the sandcarrying ability both decreased across the reservoir, causing serious siltation of the reservoir. From May 1961 to August 1962, the cross-sectional flow reached 32 million $\mathrm{m}^{3}$, about $40 \%$ of the designed storage capacity. Shoals and sandbars appeared and developed rapidly under the upper and lower sluice gates. In this period, the storage capacity was reduced from 952.5 million $\mathrm{m}^{3}$ to 712 million $\mathrm{m}^{3}$. The storage capacity

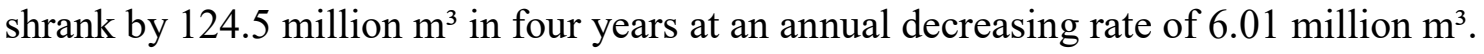

\section{(2) Spring 1965 spring 1981}

Over these 16 years, the reservoir capacity was reduced by 5.7 million $\mathrm{m}^{3}$ from 71.2 million $\mathrm{m}^{3}$ to 65.4 million $\mathrm{m}^{3}$. The annual mean loss of reservoir capacity was $360,000 \mathrm{~m}^{3}$, which is relatively small.

\section{(3) Spring 1981 spring 1990}

From 1981 to 1990 , the siltation situation worsened in the reservoir, as the reservoir capacity dropped by 683 million $\mathrm{m}^{3}$ per year. The loss rate was slightly higher than that in the previous phase. From 654.4 million $\mathrm{m}^{3}$ to 599.9 million $\mathrm{m}^{3}$, the total loss of reservoir capacity was 6.15 million $\mathrm{m}^{3}$.

\section{(4) Spring 1990 spring 2000}

This period, the Yellow River Basin witnessed continuous dry years. Under the combined effects of Longyangxia Reservoir and Liujiaxia Reservoir, the reservoir capacity was reduced from 59.29 million $\mathrm{m}^{3}$ to 40.49 million $\mathrm{m}^{3}$. The total and annual mean loss of reservoir capacity were respectively 18.8 million $\mathrm{m}^{3}$ and 1.88 million $\mathrm{m}^{3}$. From spring 1961 to spring 2000, a total of 54.7 million $\mathrm{m}^{3}$ sand deposited in the reservoir (Zhao, 2004), averaging at 1.565 million $\mathrm{m}^{3}$ per year. 
In this period, the sand amount in the reservoir was smaller than that in any of the previous periods. The reservoir capacity rebounded under the slight scouring. The storage capacity increased at an annual mean rate of 0.579 million $\mathrm{m}^{3}$ from 40.49 million $\mathrm{m}^{3}$ in spring 2000 to 48.59 million $\mathrm{m}^{3}$ in spring 2014. Throughout the five phases, the sand amount deposited in the reservoir totaled 466.6 million $\mathrm{m}^{3}$, putting the perennial mean deposition at 0.88 million $^{3}$.

\section{Calculated amount of wind-blown sand into the reservoir}

As mentioned before, the amount of wind-blown sand into the SWCP reservoir was computed through the combination of sand balance method and cross-section method, the storage capacity method and field observation.

\section{Results of the combined method}

The amount of wind-blown sand into the reservoir was computed by the sand balance method and cross-section method according to the sand outflow in 1963 2012 measured in several hydrological stations and the sand diversion data in the reservoir. The results are illustrated in Figure 2.

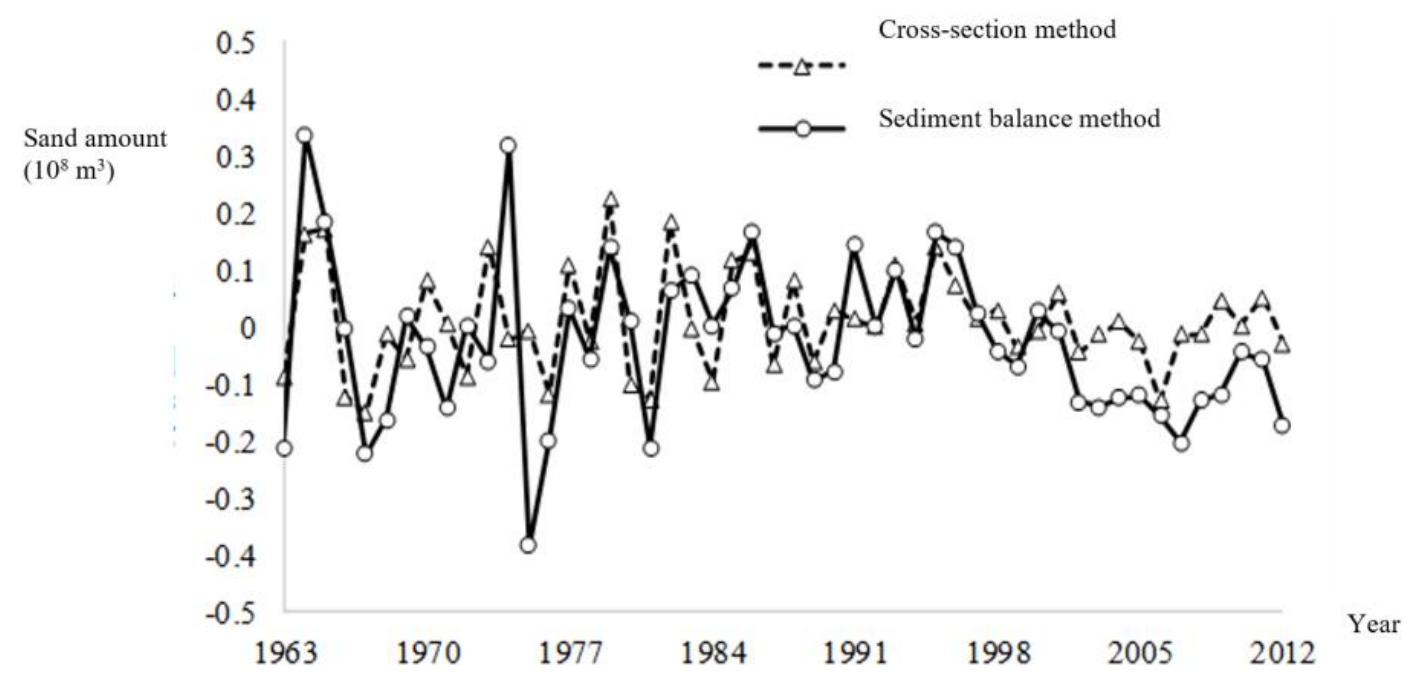

Figure 2. The annual amount of wind-blown sand into the reservoir

The results of the two methods are compared in Table 2. It can be seen that the sand amounts derived by the two methods differed by 0.345 billion tons in 50 years, i.e. 704,000 tons per year. Hence, the annual amount of wind-blown sand into the reservoir was about 704,000 tons.

Table 2. Comparison between the results of the cross-section method and the sand balance method in 1963 2012 (ton)

\begin{tabular}{c|c|c|c}
\hline Method & Trapezoidal method & Cone method & Wind-sand siltation weight \\
\hline Annual average & 0.0109 & 0.0152 & 0.0043 \\
Total & 0.505 & 0.850 & 0.345 \\
\hline
\end{tabular}




\section{Results of the storage capacity method}

From 1961 to 2014, the storage capacity of SWCP reservoir was reduced from 955.5 million $\mathrm{m}^{3}$ to 485.9 million $\mathrm{m}^{3}$; meanwhile, a total of 466.6 million $\mathrm{m}^{3}$ of sand was deposited, averaging at 123.25 million tons per year (volume weight: $1,400 \mathrm{~kg} / \mathrm{m}$ ). The variation of storage capacity through the five phases is illustrated in Table 3. The analysis on the metal element content in the river shows that the wind-blown sand was about $61 \%$ of all deposition in the river channel, accounting for $70.74 \%$ of the total amount of wind-blown sand entering the Yellow River. The annual amount of windblown sand into the Yellow River in the SWCP reservoir was about 106.28 million tons.

Table 3. Variation of storage capacity in the SWCP reservoir in 1961 2014

\begin{tabular}{c|c|c|c}
\hline Period & $\begin{array}{c}\text { Storage capacity change } \\
\left(\mathbf{( 1 0 , 0 0 0} \mathbf{~ m}^{\mathbf{3}}\right)\end{array}$ & $\begin{array}{c}\text { Storage capacity change } \\
(\mathbf{1 0 , 0 0 0} \text { tons })\end{array}$ & $\begin{array}{c}\text { Average annual change } \\
(\mathbf{1 0 , 0 0 0} \text { tons })\end{array}$ \\
\hline $1961-1970$ & -2119 & -2966.6 & -329.62 \\
$1970-1980$ & -1323 & -1852.2 & -185.22 \\
$1980-1990$ & -154 & -215.6 & -21.56 \\
$1990-2000$ & -1880 & -2632 & -263.2 \\
$2000-2010$ & -278 & -389.2 & -38.92 \\
$2010-2014$ & 1088 & 1523.2 & 380.8 \\
\hline
\end{tabular}

\section{Results of field observation}

According to the current classification of land use types, the lengths of mobile and semi-fixed sand dunes near the river section are $22.3 \mathrm{~km}$ and $3.1 \mathrm{~km}$, respectively. Through field observation, it is learned that the $22.3 \mathrm{~km}$-long mobile sand dunes released 783,900 tons, 481,100 tons, 316,600 tons and 301,900 tons of sand into the river section, respectively, in 2013, 2014, 2015 and 2016.

\section{Discussion}

To sum up, the annual mean amount of wind-blown sand into the river section obtained by the combined method was 704,000 tons (1963 2012), acquired by the storage capacity method was 106,280,000 tons (1961 2014), while observed in the field was 783,900 tons, 481,000 tons, 316,000 tons and 301,900 tons, respectively, in 2013, 2014, 2015 and 2016.

Each of the three methods have their own features. The combined method inherits the test errors, the storage capacity method faithfully reflects the long-term variation and siltation of reservoir capacity, while the field observation is limited to the period from 2013 to 2016. Synthesizing the calculation results of the three methods, it is considered that the amount of wind-blown sand into the reservoir is about $0.7 \sim 1$ million tons per year.

\section{Conclusions}

Considering the potential threats of wind-blown sand to the reservoir capacity of Sanshenggong Water Control Project (SWCP), this paper calculates the amount of 
wind-blown sand in the reservoir based on the change of reservoir capacity, using sand balance method and cross-section method. Then, the calculated amount was compared with the amount of wind-blown sand measured through field monitoring. Synthesizing the calculation results of the three methods, it is considered that the amount of windblown sand into the reservoir is about $0.7 \sim 1$ million tons per year. The research findings provide technical product for siltation prevention and reduction. The field observation of Aeolian sand is a long-term process. It is suggested that the field monitoring of Aeolian sand should be continued in the next step, and the observation types, density and frequency should be further improved to provide a solid data support platform for desert control and the development and utilization of Sanshenggong Water Control Project.

Acknowledgements. This work was supported by the National Key Research and Development Project(2018YFC0407401).

\section{REFERENCES}

[1] Chattopadhyay, S. J. D. C. G. (2011): Univariate modelling of monthly maximum temperature time series over Mann-Kendall trend analysis of tropospheric ozone using ARIMA northeast India: neural network versus Yule-Walker equation based approach. Meteorological Applications 18: 70-82.

[2] Chen, X. C., Guo, J. Y., Dong, Z., Li, H. L., Li, J. R., Wang, H. Y. (2015): Characteristics of heavy metal distribution and grain size in surface sediments of barchans dunes of the Wuhai section in Ulan Buh Desert. - Journal of Soil and Water Conservation 29(3): 4751 .

[3] Chen, X. C., Guo, J. Y., Dong, Z., Li, H. L., Li, J. R., Wang, H. Y. (2016): Grain size characteristics of dust fall in the Ulan Buh Desert. - Journal of Desert Research 36(2): 295-301.

[4] Kisi, O., Ay, M. (2014): Comparison of Mann-Kendall and innovative trend method for water quality parameters of the Kizilirmak River, Turkey. - Journal of Hydrology 513: 362-375.

[5] Liu, R., Chen, G. Y. (2016): Analysis of variation of sediment inflow and storage capacity of Sanshenggong water control project. - Inner Mongolia Water Resources 2: 10.

[6] Mao, C. Y. (2013): Review of water and sediment dispatching in the initial stage of Sanshenggong hydraulic construction project of the Yellow River. - Inner Mongolia Water Resources 5: 22-23.

[7] Thomas, D. S. G. (2011): Process, Form and Change in Drylands. - John Wiley \& Sons, Chichester.

[8] Yin, R. P., Guo, J. Y., Dong, Z., He, J. L., Li, J. R., Tian, S. M., Dai, Y. J. (2017): Wind velocity and sand flow transport characteristics of different height typical dunes in Ulan Buh Desert along the Yellow River. - Research of Soil and Water Conservation 24(5): 157-161.

[9] Youssef, F., Visser, S., Karssenberg, D. (2012): Calibration of RWEQ in a patchy landscape; a first step towards a regional scale wind erosion model. - Aeolian Research (4): 467-476.

[10] Zhao, W. B. (2004): Understanding and analysis of sediment treatment in Sanshenggong water control project of the Yellow River. - Inner Mongolia Water Resources (2): 56-58. 